\title{
Correlation Risk in the Context of Market Turbulences during the COVID-19 Pandemic and BCBS Stress Testing Principles
}

\author{
Fidelio Tata \\ Berlin School of Economics and Law, Berlin, Germany \\ Email: fidelio@fideliotata.com
}

How to cite this paper: Tata, F. (2020) Correlation Risk in the Context of Market Turbulences during the COVID-19 Pandemic and BCBS Stress Testing Principles. Journal of Mathematical Finance, 10, 612-630 https://doi.org/10.4236/jmf.2020.104036

Received: September 7, 2020

Accepted: November 1, 2020

Published: November 4, 2020

Copyright (อ 2020 by author(s) and Scientific Research Publishing Inc. This work is licensed under the Creative Commons Attribution International License (CC BY 4.0).

http://creativecommons.org/licenses/by/4.0/

\section{(c) (i) Open Access}

\begin{abstract}
Correlations play an important role in the risk management of banks. Changes of correlation are an important element of an adverse (stress) scenario in the BCBS framework. The purpose of this paper is to show how correlation is plagued by a number of issues that include volatility, directionality and autocorrelation. To that end, we analyze to which degree directionality and autocorrelation of correlation remove diversification benefits when they are most needed, i.e. in a crisis, and how autocorrelation amplifies correlation and makes it more persistent, creating the illusion of stable, reliable correlation levels. Furthermore, we exemplify changing correlations during the COVID-19 pandemic looking at a number of different markets. Our results suggest that prudent bank risk management should be cautious when calibrating its risk models to historical correlation levels. Market price-based stress tests should include various levels of assumed correlation as inputs to the statistical models used to assess a bank's viability. We propose how banking supervisors and macro prudential authorities should challenge banks' correlation assumptions and assess the rigor of applying them.
\end{abstract}

\section{Keywords}

Banking Regulation, Basel, Financial Modelling, Market Microstructure, Risk Management, Value-at-Risk

\section{Introduction}

Correlations play an important role in the risk management of banks. On a portfolio level, diversification benefits are typically measured by the degree of correlation between individual securities; on a balance sheet level, correlation between various balance sheet items measures offsetting price effects to interest 
rate and credit spread shocks; and on a bank-wide level, correlation to other market participants' behavior indicates the liquidity risk during a crisis.

One of the most widely used frameworks of risk management in the financial markets is Value-at-Risk (Var). In it, VaR estimates the risk of a combination of positions under explicit consideration of partially offsetting price movements. The degree to which risk is mitigated by diversification is modeled through assumed correlations between assets. Increasing correlation parameters in a VaR model will lead to a higher risk assessment for the overall portfolio. Correlation, a measurement of the dependence or independence of financial time series and typically estimated quantitatively as the linear correlation coefficient of return, has always known to be plagued by a number of shortcomings. The most prominent one is that correlations between financial assets vary over time. Historical correlation (i.e. correlation estimated from past data) depends on the phase of the economic cycle and the length of the time series, among other things. Implied correlation (i.e. correlation parameters backed out of market prices of instruments) is much harder to observe than, say, implied volatility due to the scarcity of correlation products traded. There are multiple other, more nuanced, issues in the field of correlation, such as directionality (correlation increasing during a crisis) and autocorrelation (trending correlation).

Both, banks and bank supervisors have been aware of the issues surrounding correlation for a long time but have only recently placed more emphasis on this topic. Embedded in stress test principles by the Basel Committee on Banking Supervision (BCBS) from almost 10 years ago, and just recently updated, correlation is no longer an obscure model parametrization of minor relevance and has claimed center stage in a rigid stress testing framework.

To address the problems when using constant correlation measures in risk management we analyze the effects of changes in correlation, identify reasons for autocorrelation of correlation, discuss changes in correlation caused by the COVID-19 pandemic and suggest how supervisors can challenge banks' correlation assumptions and assess the rigor of applying them.

In Section 1, we present the current supervisory framework with respect to stress testing principles. In Section 2, we discuss how correlation is estimated and what impact volatility of correlation has. In Sections 3 and 4, we discuss directionality and autocorrelation of correlation, respectively. Section 5 analyses the impact of the COVID-19 pandemic on various correlation measures. In Section 6, we illustrate banking supervisors' and macro prudential authorities' role in challenging banks' correlation assumptions as well as confirming the rigor of applying them.

\section{Supervisory Framework}

The Basel Committee on Banking Supervision (BCBS) laid out its stress test principles in May 2009 [1] and on 17 October 2018 [2]. The principles focus on the core elements of stress test frameworks, in particular goals, governance, processes, 
methodology, resources, and documentation. The new principles are addressed to banks and national supervisors ([3] pp. 20-21).

A stress test is the evaluation of a bank's financial position under a severe but plausible scenario to assist in decision making process. Pillar 1 (minimum capital requirements) of the Basel II framework requires banks using the Internal Models Approach to determine market risk capital to have in place a rigorous stress testing program.

BCBS (2009) already laid out a list of 21 over-arching principles for sound stress testing practices and supervision with a view towards application to large and complex banks. In particular, principle \#11 called for systematically challenging the effectiveness of risk mitigation techniques: "The performance of risk mitigating techniques, like hedging, netting and the use of collateral, should be challenged and assessed systematically under stressed conditions when markets may not be fully functioning and multiple institutions simultaneously could be pursuing similar risk mitigating strategies" ([1] p. 15). Risk mitigating techniques often critically depend on an assumption about correlation between various financial assets; this could be explicitly through the assumption of correlation coefficients in the context of portfolio diversification or implicitly by assuming stable spreads and bases between different "legs" of a trade, hedge or business model.

BCBS (2018) presented an updated list of principles that are meant to be guidelines for internationally active banks, when stress testing is embedded as a critical component of sound risk management and supervisory oversight. While correlation risk is not explicitly mentioned, a number of stress testing principles are relevant to this topic. Principle \#4 calls for the stress testing framework to capture material and relevant risks and asks banks to particularly pay attention to risk concentrations. Those are often identified, or fail to be identified, by the implicit or explicit assumption of correlation between assets. For example, a European-wide portfolio of consumer loans may appear to be highly diversified with little risk concentration until correlation between country-specific loans increases in a credit crisis and risks are suddenly highly concentrated. Principle \#7 demands that models and methodologies to assess the impact of adverse scenarios should be appropriate, potentially incorporating "cross-bank features such as system-wide feedback or contagion". Such behavior, when so-called fire sales are conducted and market participants execute similar de-leveraging and hedging techniques, typically leads to an increase in correlation across title-specific instruments and asset classes in the market.

Changes of correlation are an important element of an adverse (stress) scenario. BCBS (2017) defines a stress scenario as "a set of economic and financial conditions (...) which is designed to stress the financial performance of a financial system, sector, institution, portfolio or product" ([4] annex 1). A particular form of stress scenario is conducted in a market price-based stress test, defined as a "methodology that uses primarily market data (e.g. share prices, volatilities, 
spreads) and statistical models to assess an institution's viability" ([4] annex 1]. If correlation assumptions are changed, similarly to the change of volatility assumptions, stress losses may be the consequences. BCBS defines those a "estimates of negative income that deplete capital resulting from the stress test, [which] depend on the assumptions and inputs of the underlying stress test and can be represented by different metrics, e.g. depletion of capital (regulatory or otherwise), reduction of revenues, and run-off of funding" ([4] annex 1].

In January 2019, BCBS published their minimum capital requirements for market risk [5]. For the first time, the issue of correlation has been explicitly covered in great detail. In fact, the term "correlation" is mentioned 162 times. One area, where correlation plays a role is in the so-called standardized approach for market risk. For example, to "to address the risk that correlations increase or decrease in periods of financial stress, the aggregation of bucket level capital requirements and risk class level capital requirements per each risk class for delta, vega, and curvature risks (...) must be repeated, corresponding to three different scenarios on the specified values for the correlation parameter[s]" ([5] MAR21.6). Another area where banks have to consider correlation is when conducting risk factor modeling and backtesting: "Banks must periodically demonstrate the appropriateness of their modelling methodology by comparing the risk factor returns forecast produced by the risk management model with actual returns produced by front office prices. Alternatively, a bank could backtest hypothetical portfolios that are substantively dependent on key risk factors (or combinations thereof). This risk factor backtesting is intended to confirm that risk factors accurately reflect the volatility and correlations of the instruments in the risk model" ([5] MAR99.2(24)).

Correlation assumptions are directly linked to a bank's capital requirements. Pillar 2 of the BCBS standards requires financial institutions to conduct an ICAAP (internal capital adequacy assessment process) stress test, which allows the supervisor to set a bank-specific acceptable amount of capital requirements (capital hurdle rate). If a change in correlation assumptions leads to an increase of risk, e.g. by increasing Value-at-Risk ( $\mathrm{VaR})$ measures, banks will be forced to establish buffers and provisions against such an adverse scenario.

\section{Correlation Estimates and Correlation Volatility}

Most risk managers are mandated to establish an estimate for correlation between assets held on the balance sheet, either as part of their internal risk management system (e.g. VaR) or for regulatory reporting reasons. At first sight, using implied correlations extracted from traded financial market products would appear to be the most convenient solution. However, there are at least two reasons why this approach is problematic. First, few correlation products are actively traded in the market with sufficient liquidity. For example, it is unlikely that a Treasurer of a commercial bank will find price quotes of liquid structured products that allow for the extraction of implied correlations between, say, cor- 
porate bank loans and corporate bonds. Second, implied correlations in the physical measure can be used only as estimates under the risk-neutral measure. It has been shown that implied correlation is, on average, higher than realized correlation [6] [7], meaning that there is a correlation risk premium.

An alternative approach typically used by practitioners in the field of portfolio risk management is to conduct a historical analysis of past volatility ${ }^{1}$ and correlation and then to use historical data as proxies for the expected volatility and correlations over the next time period. For convenience, consider the case of a stylized portfolio of two asset classes, $A$ and $B$. Those could, in the case of a bank risk manager, be corporate loans and corporate bonds. Applying standard Markowitz portfolio theory, the risk manager would aim to estimate the volatility of a combined portfolio

$$
\mathbb{E}_{t}\left(\sigma_{A, B} \mid w_{A, B}, \tilde{\sigma}_{A}, \tilde{\sigma}_{B}, \tilde{\varrho}_{A, B}\right)
$$

where $\mathbb{E}_{t}(\cdot)$ denotes an expectation at time $t$, a tilde $(\sim)$ placed on top a variable indicates its stochastic nature, $w_{A, B}$ reflects portfolio weights, $\sigma$ standard deviations and $\varrho_{A, B}$ the correlation coefficient between $A$ and $B$.

A commonly used approximation of arriving at a solution for the expected portfolio risk is to assume

$$
\mathbb{E}_{t}\left(\sigma_{A, B} \mid w_{A, B}, \tilde{\sigma}_{A}, \tilde{\sigma}_{B}, \tilde{\varrho}_{A, B}\right) \cong \sigma_{A, B} \mid w_{A, B}, \mathbb{E}_{t}\left(\tilde{\sigma}_{A}\right), \mathbb{E}_{t}\left(\tilde{\sigma}_{B}\right), \mathbb{E}_{t}\left(\tilde{\varrho}_{A, B}\right)
$$

whereas the portfolio risk is then calculated as

$$
\sigma_{A, B}=\sqrt{\left(w_{A} \mathbb{E}_{t}\left(\tilde{\sigma}_{A}\right)\right)^{2}+\left(w_{B} \mathbb{E}_{t}\left(\tilde{\sigma}_{B}\right)\right)^{2}+2 \cdot w_{A} \cdot w_{B} \cdot \mathbb{E}_{t}\left(\tilde{\varrho}_{A, B}\right) \cdot \mathbb{E}_{t}\left(\tilde{\sigma}_{A}\right) \cdot \mathbb{E}_{t}\left(\tilde{\sigma}_{B}\right)}(3)
$$

Expectations at time $t$ for standard deviations $\sigma$ and correlation coefficients $\varrho$ are then replaced by historical standard deviations and correlation coefficients observed in the previous period $t-1$ :

$$
\begin{aligned}
& \mathbb{E}_{t}\left(\tilde{\sigma}_{A}\right)=\sigma_{A, t-1} \\
& \mathbb{E}_{t}\left(\tilde{\sigma}_{B}\right)=\sigma_{B, t-1} \\
& \mathbb{E}_{t}\left(\tilde{\varrho}_{A, B}\right)=\tilde{\varrho}_{A, B, t-1}
\end{aligned}
$$

To illustrate the effect of uncertainty about the proper correlation coefficient on the portfolio risk calculations we are suggesting a simple numerical example. Suppose $w_{A}=w_{B}=50 \%, \sigma_{A, t-1}=\sigma_{B, t-1}=20 \%$ and $\tilde{\varrho}_{A, B, t-1}=-0.5$. The resulting portfolio risk $\sigma_{A, B}$ can be calculated as $10 \%^{2}$.

It is important to acknowledge that the expected portfolio risk, when calculated this way, is just an approximation. The expected risk calculated from uncertain variances and correlations does not equal the risk calculated from expected variances and expected correlations, i.e.

$$
\mathbb{E}_{t} f\left(w_{A, B}, \tilde{\sigma}_{A}, \tilde{\sigma}_{B}, \tilde{\varrho}_{A, B}\right) \neq f\left(w_{A, B}, \mathbb{E}_{t}\left(\tilde{\sigma}_{A}\right), \mathbb{E}_{t}\left(\tilde{\sigma}_{B}\right), \mathbb{E}_{t}\left(\tilde{\varrho}_{A, B}\right)\right)
$$

${ }^{1}$ Volatility is measured as the standard deviation, or the square-root of variance.

${ }^{2}$ The reduction of portfolio risk from $20 \%$ (individual asset risk) to $10 \%$ is due to the diversification effect, triggered by a correlation coefficient that is significantly lower than 1 . 
The difference between those two is the result of Jensen's inequality and is akin to the convexity adjustment for bond yields, measuring the difference between the expected bond yield and the yield of the expected bond price. An important question to ask at this point is whether ignoring the stochastic nature of correlation and by fixing it to its expected value, the effect of portfolio diversification is over- or underestimated. Because if this approximation overestimates the diversification effect, prudent risk management would require to adjust the correlation input accordingly.

In Figure 1, we plot the calculated portfolio risks for our sample portfolio $\left(\sigma_{A, B}\right)$, using different correlation coefficients. The red square represents the portfolio risk of $10 \%$ resulting from using the expected correlation coefficient of -0.5 . The concave nature of the portfolio risk graph illustrates the nonlinear relationship between changes in correlation and portfolio risk. A decline in correlation creates a higher diversification benefit that an equivalent increase in correlation causes a reduction of diversification benefit. If instead of assuming a $100 \%$ probability of correlation being -0.5 , for illustration purpose we assume an equal (50\%) probability of a -0.9 and a -0.1 correlation coefficient, respectively (blue triangles), the resulting average expected portfolio risk drops from $10 \%$ to roughly $9 \%{ }^{3}$. Thus, diversification benefits increase with the variability of correlation coefficients.

Due to

$$
\mathbb{E}_{t}\left(\sigma_{A, B} \mid w_{A, B}, \tilde{\sigma}_{A}, \tilde{\sigma}_{B}, \tilde{\varrho}_{A, B}\right) \leq \sigma_{A, B} \mid w_{A, B}, \mathbb{E}_{t}\left(\tilde{\sigma}_{A}\right), \mathbb{E}_{t}\left(\tilde{\sigma}_{B}\right), \mathbb{E}_{t}\left(\tilde{\varrho}_{A, B}\right)
$$

we can conclude that it is conservative to use expected correlation coefficients as a basis for calculating portfolio risk, which, if anything, underestimates the portfolio diversification benefits.

\section{Directionality of Correlation}

Empirical evidence suggests that correlation between assets (and asset classes) not only varies significantly over time, but also increases during times of financial crisis ${ }^{4}$. This is particularly problematic from a risk management point of view because it suggests that diversification benefits are diminishing precisely when they are needed the most ${ }^{5}$. [13] finds that "observed correlations are higher than normal correlations on the downside and lower on the upside; in other words, international diversification works during good times-when it is not needed-and disappears during down markets. When both markets [US and World Ex-US equity markets] are up by more than one standard deviation, the

${ }^{3}$ Portfolio risk is $4.47 \%$ for an assumed correlation coefficient of $-0.9 \%$ and $13.42 \%$ for an assumed correlation coefficient of -0.1 . Thus, the average is $8.94 \%$.

${ }^{4}$ See, for example [8] [9] [10]. [11] analyzes the correlation between commodities and stocks and find that correlations increase during periods of high market volatility, such as the financial market crisis of 2007/2008.

${ }^{5}$ There is even some evidence that market participants try to mitigate the risk of increasing correlation during a crisis by overweighting assets that perform well in states where asset correlations are high, causing them to trade with a correlation risk premium. See, e.g. [12]. 


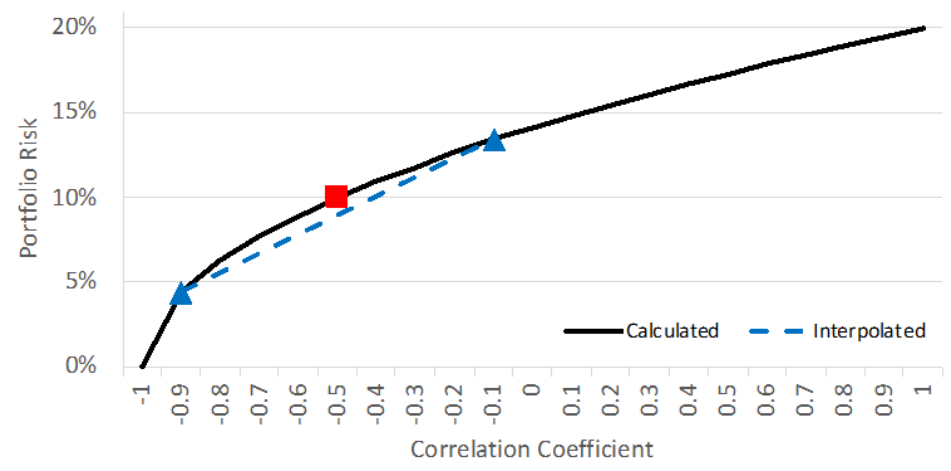

Figure 1. Concave portfolio risk.

correlation between them is $-17 \%$. When both markets are down more than one standard deviation, the correlation between them is $+76 \%$. And in times of extreme crisis, when both markets are down by more than two standard deviations, the correlation rises to $+93 \%$ compared to $+14 \%$ for the corresponding bivariate normal distribution".

It is not difficult to see why correlations between many financial market assets are changing significantly during periods of stress. During "normal" times, most trading activity is triggered by random events, e.g. a bank entering into an interest rate (IR) swap, a pension fund buying particular types of securities or a corporate customer hedging some currency exposure. When this kind of "noise" orders are directed at broker/dealers, they will use discretion to hedge (i.e. balance their trading book) according to where they see relative value. This causes flow to spread across various financial market products, limiting the knock-on effect of one transaction in a particular product on another specific instrument. For example, one broker/dealer may hedge a 9-year IR swap with a corporate customer by entering into an offsetting 10-year IR swap in the inter-dealer market, another may trade in 10-year on-the-run government bonds, yet another may establish a position in 10-year corporate bonds.

However, during times of market stress ${ }^{6}$, market participants are often forced by institutional rules to act in a non-discretionary way. A mutual fund manager facing significant net redemptions must liquidate part of the portfolio in a proportional matter; a broker/dealer forced to scale down risk limits on short notice will likely, as a first step, proportionally reduce risk limits to most of its trading books, forcing trading desks of all kind of asset classes to sell off inventory; investor sentiment switching from risk-on to risk-off causes portfolio rebalancing flows from risky assets into what are perceived to be less-risky assets (e.g. stocks into bonds), creating simultaneously-executed flows in otherwise hardly correlated markets. A crisis typically limits market participants' ability to postpone trades, to look for proxy-hedges, or to view the other market participants' beha-

${ }^{6}$ One form of stress would be a significant deterioration in asset prices, forcing market participants to realize mark-to-market losses and to adjust their leverage according to capital requirements; another form of stress would simply be a higher volatility in the market, resulting calculated VaR's to exceed VaR limits and causing deleveraging activity. 
vior as a cause for relative value opportunities that suggest entering into opposite transactions. Instead, heard-like behavior can be observed. Lock-step trade executions then create high correlations between assets that exhibited only little joint-movement prior to the crisis.

There are two recent market developments that are likely to be responsible for an increase in directionality of correlation with respect to general market levels. The first is the steady climb in passive (i.e. index-linked) investments ([14] p. 10) reports an increase of index funds as a percentage of total equity mutual fund assets from $4 \%$ in 1995 to $34 \%$ in 2005 . If redemption calls force index funds to liquidate assets, they need to do so proportionally to the index decomposition, increasing correlation between instruments that are part of the same index. The second development to be identified as a possible culprit for increasing directionality in correlation is electronic trading. It is estimated that computerized trading (i.e. that is not based on a fundamental view) already accounts for roughly $85 \%$ of all trading volume ${ }^{7}$. Electronic trading, based on pre-programmed trading algorithms and according to similar models, not only creates heard-like behavior that is blazingly fast, but also makes the market move in unison. See [15].

\section{Autocorrelation of Correlation}

While most risk-management systems treat correlation as an input variable, correlation coefficients are in practice typically held constant over several calculation and/or reporting periods (e.g. several months). Loosely speaking, treating correlation that way is to say that today's best correlation estimate is yesterday's actually observed or calculated correlation coefficient ${ }^{8}$, i.e.

$$
\mathbb{E}_{t}\left(\varrho_{t} \mid \varrho_{t-1}, \varrho_{t-2}, \cdots\right)=\varrho_{t-1}
$$

What causes practitioners to model correlation in this fashion is likely the observation (drawn from "quiet" market periods) that correlation coefficients are highly persistent. In fact, work by [17] indicate that first-order autocorrelations for correlation from equity options are between 0.97 and 0.993 .

We will now illuminate how autocorrelation of correlation creates a self-feeding and amplifying effect of an exogenous increase in correlation (e.g. due to an isolated portfolio trade or the execution of statistical arbitrage trades by a hedge fund) which then increases correlation beyond what it would have been if correlation were a pure random walk. Taking a market microstructure point of view, we will illustrate this by considering the market behavior of three archetypes of traders: market makers, hedgers and arbitrageurs.

\subsection{Market Makers}

Market making provides immediacy in execution by filling gaps arising from ${ }^{7}$ Estimates by a J.P. Morgan analyst, quoted in [15].

${ }^{8}$ More formally, one would assume the correlation process to form a martingale with respect to past correlations. For a more detailed discussion of a martingale as a particular form of a random walk, and how to test for it, see e.g. [16]. 
imperfect synchronization between arrivals of buyers and sellers [18]. Market makers will quote prices at which they are willing to buy (bids) or sell (offers) at a given trading size. Nowadays many, if not the majority of all, quoted financial instruments are set by algorithms of an electronic broker/dealer platforms. For example, the quotes of a so-called off-the-run (OFR) government bond ${ }^{9}$ are based on the yield of the on-the-run (OTR) government bond plus/minus a spread that is only occasionally adjusted throughout the day by the market makers in control of the quoting engines. With the proliferation of electronic market making, more and more financial instruments are linked to each other, in terms of price quotes, through clearly defined mathematical formulas. The process of pricing less actively traded financial instruments on quoted prices of more frequently traded comparable instruments is called matrix pricing. Matrix pricing can link prices of more than two instruments. For example, the spread between the OTR and OFR government bond can be further explained by the duration difference (as the OTR has been issued after the OFR and has a slightly longer remaining maturity) and also depends on the slope of the yield curve. The slope of the yield-curve, in turn, can be estimated by comparing two points on the swap curve (that is often used as a proxy for the yield curve in general). If the quoting engine for the OFR government bond explicitly takes the slope of the swap curve into consideration, the pricing of OFR government bonds no longer just depends on the pricing of OTR government bonds, but also on swap prices. Through those pricing algorithms, price shocks to one instrument class are propagated, within fractions of a second, into other asset classes, increasing the correlations between them. Note that correlation becomes a self-fulfilling property. Pricing engines would only calculate prices of less liquid instruments on the basis of other, more liquid instruments if there is a presumably high correlation between them; and if this is done, the quasi-unison price behavior of those linked instruments will produce a high actual correlation between them. By baking an assumed correlation into a matrix pricing framework, the correlation becomes real.

Conversely, if correlation is no longer assumed to be sufficiently high between two instruments (either because actual correlation declined as of lately or there is the assumption that it will decline in the future), market maker will shy away from pricing one asset on the basis of the other asset's price quotes. To illustrate this, let's look at two distinct yield curves, the government bond and the swap yield curve. The difference between the yield of a government bond and a maturity-matched interest-rate swap is called "swap spread". If swap spreads were to be constant, the swap rate could be quoted based on the government bond yield (e.g. the yield of the OTR government bond) and a fixed spread. Indeed,

${ }^{9}$ The on-the-run (OTR) bond is typically the most recently issued government bond of a particular maturity. If a new government bond is issued for the same maturity, the former OTR becomes an off-the-run (OFR) bond. Typically, OTR bonds are more liquid that OFR bonds, can be financed in repo at more attractive levels and are preferred over OFR when it comes to hedging. 
there have been periods for which swap spreads have been fairly stable, moving only by a fraction of a basis point every day. During those times, quoting swaps on the basis of government bonds seemed appropriate and correlations between government bonds and equivalent-maturity swaps were almost 1 . But when historical correlations started to drop and government and swap rates did no longer move in lock steps ${ }^{10}$, market makers quickly adjusted their pricing engines such that other factors were included to derive the price of one instrument from the other. By doing so, prices were no longer as closely related as before, leading to correlations between them to drop even further. Thus, a lack of trust in a sufficient correlation between asset prices also has a self-fulfilling property of creating a low actual correlation.

\subsection{Hedgers}

Hedgers are market participants tasked with reducing the market risk of a financial position. In theory, the risk of the position could be eliminated completely by unwinding the position (i.e. selling off the assets) or by entering into an offsetting position created with same underlying instrument. In practice, this is often not feasible for a number of reasons, including the underlying not being liquidly traded, because of transaction cost, for regulatory or client-relationship reasons, or because only one particular risk component of the underlying position should be hedged (e.g. the interest rate risk, but not the credit risk).

Hedging aimed at reducing risk by entering into a transaction involving similar instruments with the hope/expectation that their price behavior is highly correlated to that of the underlying is typically referred to as proxy-hedging. Proxy-hedging needs to weight different objectives against each other, such as immediacy, liquidity, cost efficiency and hedge effectiveness ${ }^{11}$. This is always a user- and situation-specific compromise, an exercise characterized often by practitioners to be just as much art as science. The first step to proxy-hedging is to identify a suitable proxy ${ }^{12}$. The choice may vary over time. What used to be a good proxy at some point may become unsuitable at a later juncture (e.g. driven by structural changes in the market such as Brexit). Apart from using common sense and observing how hedging is conducted by other market participants, hedgers attach great importance to historical correlations between the underlying and the hedge instrument.

All else being equal, high correlation favors a financial asset to be used as a proxy-hedge, exposing it to price and flow shocks of the hedged underlying and resulting in a persistently high, or even increasing, correlation. If, on the other

\footnotetext{
${ }^{10}$ This could happen due to a significant change in government bond issuance (i.e. supply and demand) or changes in credit spreads, among many other factors.

${ }^{11}$ Specific accounting requirements need to be observed when the hedge should qualify for hedge accounting, such as the $80 \%-125 \%$ rule (International Accounting Standards section 39R.88).

${ }^{12}$ Other elements, such as determining the proper hedge ratio, the timing of execution, choice of execution venue, frequency of hedge adjustment, are not subject to our discussion, although they are equally important.
} 
hand, correlation falls below a level perceived to be sufficient for proxy-hedging, the instrument is no longer used as a proxy-hedge and correlation will fall even further.

\subsection{Arbitrageurs}

Arbitrageurs engage in arbitrage, whereas we go beyond the academic risk-free arbitrage definition and include so-called statistical arbitrage that is commonly explored by hedge funds, proprietary trading desks and other arbitrage units. Statistical arbitrage is based on statistical analysis, utilizing vast amounts of computational resources and huge data sets, to detect short-term deviations from some sort of assumed fair-value, or mean ${ }^{13}$.

To illustrate the effect of statistical arbitrage on the persistence and autocorrelation of correlation we are focusing on pairs trading, a strategy that involves two historically correlated financial instruments ${ }^{14}$. Through machine learning or other computer-based methods, a "pair" of instruments is identified for which in the past a high degree of joint-movement, or correlation, has been observed. In the past can be defined as the last couple of years or as short as the last couple of seconds. In the world of high-frequency trading, where price patterns are formed within fractions of a second, a pair could be two otherwise unrelated instruments that get jointly traded as part of a trade execution of a significant market participant. If, for example, an institutional investor may decide to scale into a buying program of a foreign-currency corporate bond on a cross-currency asset swap basis, then the price dynamics of the corporate bond and the foreign exchange rate may temporarily exhibit higher-than-usual correlation. This transient correlation will likely persist as long as the buying program continues. High-frequency data mining of statistical arbitrage algorisms may pick up on this correlation, create a temporary "pair" between the now highly correlated instruments and start executing pair trades. Let's a assume the buying program of the institutional investor involves buying chunks of the somewhat illiquid foreign-currency corporate bonds (e.g. by placing limit-buy-orders and waiting them to be filled) and then entering into notional-equivalent cross-currency asset swaps with selected broker/dealers in the OTC market. Because of the latency between corporate bond buying and swap transaction, a low-latency ${ }^{15}$ statistical arbitrage hedge fund could observe the order flow in corporate bonds and transmit algorithm-based orders to the swap market before the institutional investor's asset swap transaction creates a price impact in the derivative or foreign

\footnotetext{
${ }^{13}$ Examples for market participants conducting statistical arbitrage are the hedge funds Renaissance Technologies LLC (with roughly $\$ 84$ billion in assets under management) and Two Sigma Investments LP (roughly $\$ 52$ billion in assets under management). Both hedge funds are known to employ mathematicians, statisticians, pure and experimental physicists and computer scientists to apply artificial intelligence and machine learning on supercomputers.

${ }^{14} \mathrm{~A}$ detailed examination of pairs trading is provided in [19].

${ }^{15}$ Low latency is created in a number of ways, including exchange co-location of trade execution servers, advanced low-latency customizable logic chips running fast/efficient algorithms on blade computers or dedicated microwave networks (gaining a 3-millisecond advantage on a distance New York-Chicago).
} 
exchange market.

The more statistical arbitrage traders observe a high correlation between two assets and start trading them as a pair, the higher correlated the pair becomes. A random price shock in one instrument will then create knock-on price effects on the other instrument through pair trading, keeping correlation high even though the causal relationship between the two instruments has long been lost.

\subsection{Combined Effect}

Market makers, hedgers and arbitrageurs exhibit the same behavior as far as their reaction to high observed correlation is concerned: If correlation between two assets is above a certain threshold, those assets are quoted/traded in unison, creating a self-feeding and amplifying effect on correlation. This dynamic is illustrated in a simplified manner in Figure 2. We are looking at the correlation between three-month US Government (Treasury bill) yields and three-month TED spreads ${ }^{16}$ from 2001 to 2007 . The dotted line proposes a correlation threshold of 0.95 , above which we exemplarily propose market participants (market makers, hedgers and arbitrageurs) to assume substitutability between the assets. This would then cause correlation, once increased from sub-0.95 levels to 0.95 , to increase even further and ultimately remain at levels close to 1 (represented by red arrows).

\section{Correlation during the COVID-19 Pandemic}

We are now having a closer look at what happened to selected correlations during the first half of 2020, a period that was predominately influenced by the marked turbulences on the back of the COVID-19 pandemic. Figure 3 exemplifies the volatility in the market, displaying the S\&P 500 US stock market index since 2017. Between February 21, 2020 and March 23, 2020, the index fell by more than $30 \%$, only to reverse most of that move within the following three months.

The first correlation to consider is one between identical asset classes, but in different geographical regions. We chose the correlation between one of the broadest equity market indices in the US, the S\&P 500 index, and the corresponding index in Germany, the DAX. Figure 4 displays the correlation coefficient for a rolling correlation with one year of daily data. What is quite obvious is that the COVID-19 pandemic has not made much of a difference in correlation that started of around 0.95 in 2020 and never fell below 0.9 in the months to follow. Intuitively, this makes perfect sense, as the COVID-19 pandemic is a global crisis that affects pretty much all countries around the globe. Most corporations that are part of the S\&P 500 and the DAX indices are large, globally operating firms that are impacted by the political responses to the COVID-19 pandemic on both sides of the Atlantic.

${ }^{16}$ The TED (short for "Treasury-Eurodollar") spread is the difference between the tree-month Treasury bill rate and the three-month LIBOR rate. It is widely used as an indicator of credit risk. 


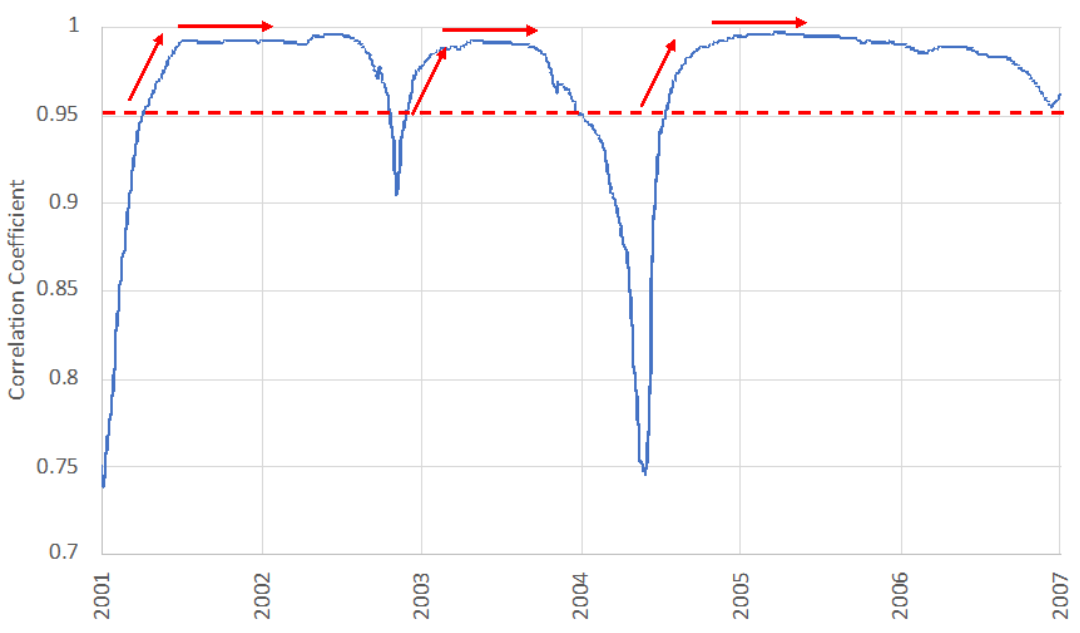

Figure 2. Illustration of self-feeding effect of correlation between the 3-month US Government yield and 3-month TED spreads ${ }^{17}$.

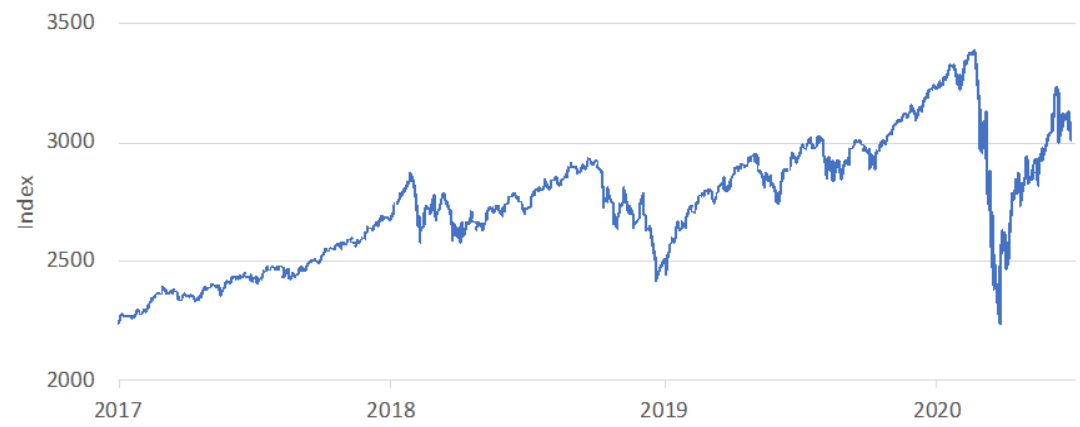

Figure 3. S\&P 500 index $^{18}$.

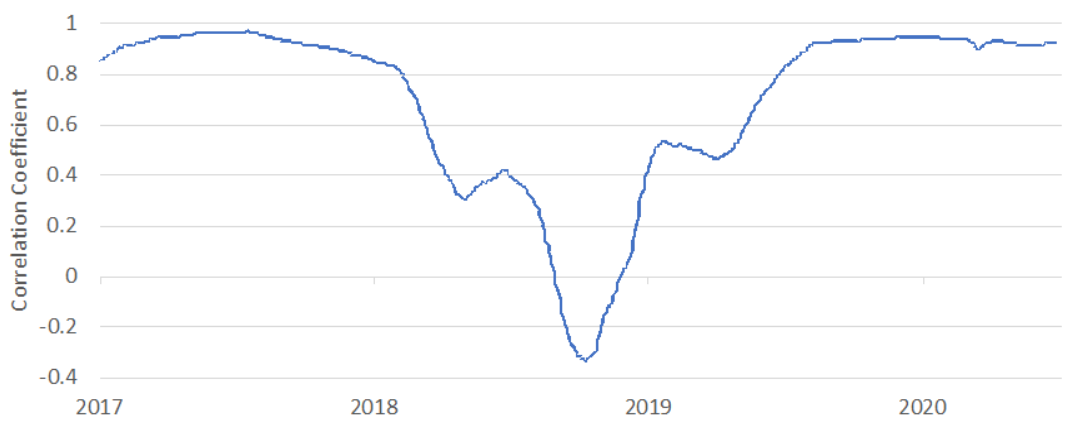

Figure 4. Rolling correlation between S\&P 500 and $\mathrm{DAX}^{19}$.

A second type of correlation to consider is one between an individual security and the whole market. We use Alphabet Inc. (Google) vs. the S\&P 500 index as an example. Results are shown in Figure 5. Correlation coefficients are positive and quite high ( 0.7 or larger). During the first half of 2020 , correlation coeffi${ }^{17}$ Rolling one-year correlation calculated from daily data; source: Federal Reserve Bank of St. Louis Economic Data.

${ }^{18}$ Data up to 26 June 2020; source: Yahoo! Finance.

${ }^{19}$ Rolling one-year correlation calculated from daily data; data up to 26 June 2020; source: Yahoo! Finance. 
cients dropped slightly, although not in an unusually large fashion when compared to previous declines (such as in June/July of 2019). Part of the moderate decline in correlations can be explained by the fact that Google, being one of the five most prominent technology companies, often referred to as $\mathrm{FAANG}^{20}$, which partially benefited from the COVID-19 crisis.

The next correlation to be looked at is one between different asset classes, but within the same geographical region. We use the S\&P 500 index as a broad representation of the US stock market again and compare it to the 10-year US Government bond yield. Results are reported in Figure 6. Correlations between stocks and interest rates are notoriously unstable. This is because there is a conflicting connection between stock prices and interest rates. On one hand, a decline in interest rates increases the present value of expected dividend payments (due to lower discount factors); on the other hand, are low interest rate-environments often associated with a weak economy that leads to lower expected dividends in the first place. The COVID-19 crisis not only caused a significant change in correlation, but also a change in sign (from around -0.5 to +0.5 ). This is because the fear of a recession and a long-term downturn in the economy pushes both interest rates and stock prices lower.

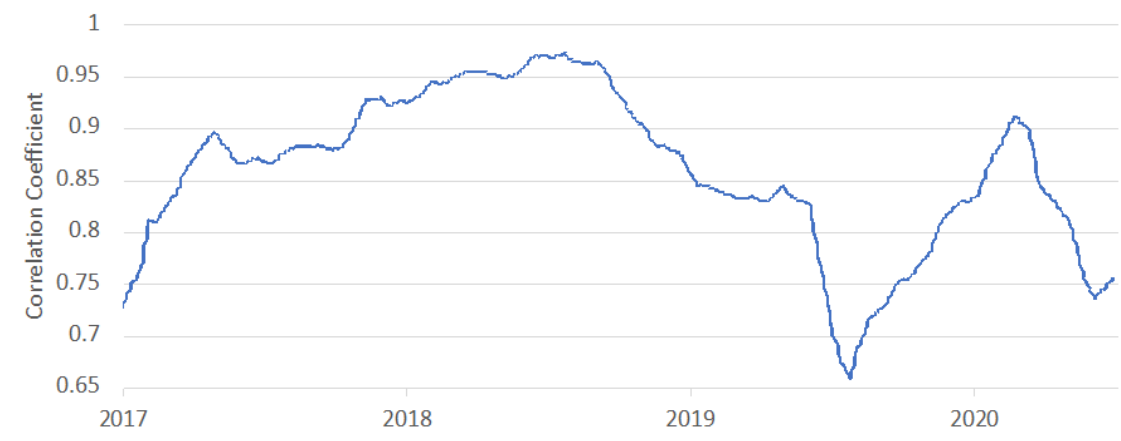

Figure 5. Rolling correlation between S\&P 500 and Google ${ }^{21}$.

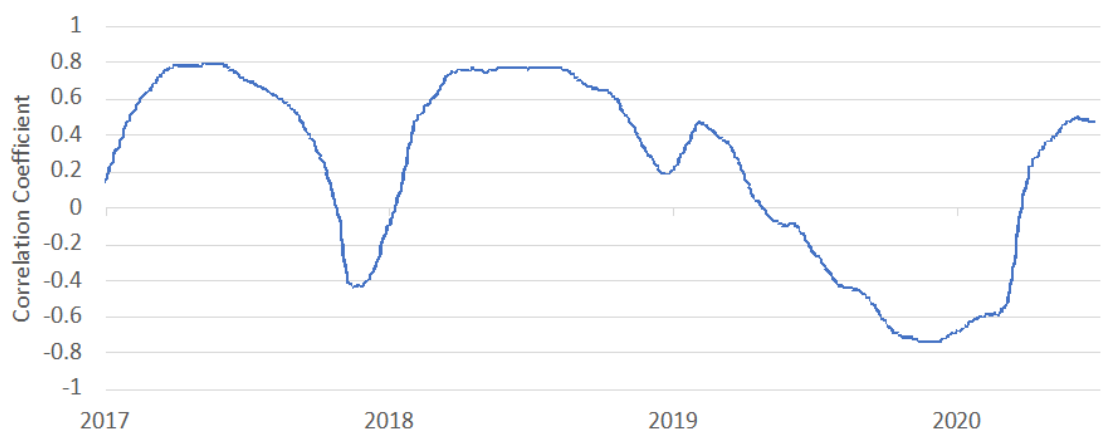

Figure 6. Rolling correlation between S\&P 500 and 10-year US Government bond yield ${ }^{22}$.

${ }^{20}$ Facebook, Amazon, Apple, Netflix and Alphabet (Google).

${ }^{21}$ Rolling one-year correlation calculated from daily data; data up to 26 June 2020; source: Yahoo! Finance.

${ }^{22}$ Rolling one-year correlation calculated from daily data; data up to 26 June 2020; source: Yahoo! Finance. 
Finally, let's look at credit spreads. As in Figure 2, we chose the correlation between three-month US Treasury bill yields and three-month TED spreads. Short-dated interest rates and short-dated credit spreads tend to be positively correlated during normal (calm) times, but then exhibit a stark decline in correlation during times of crisis (turmoil regimes). Figure 7 illustrates this. What is quite interesting is that the COVID-19 pandemic had not a similar effect on correlation as the previous financial market turbulences since 1987 . This may be best explained by the fact that previous market crises were, to a large degree, banking crises, while the COVID-19 pandemic did not cause a disproportional threat to banks. TED spreads are based on bank funding rates and, thus, reflect credit risk of the banking sector.

\section{Implications for Supervisors}

While the ball is clearly in the banks' court as far as conducting stress test frameworks is concerned, banking supervisors and macro prudential authorities play an important role in challenging banks' correlation assumptions as well as assessing the rigor of applying them. This shall be illustrated for three distinct areas:

\subsection{Proper Calibration of Correlation Parameters}

Scenario designs, being part of stress test analyses, should be based both on historical data as well as hypothetical scenarios. Historical data are typically used to calculate (rolling) correlation estimates. The range of those correlations then serves as a basis to pick a severe, but plausible, input for the stress test. However, there appears to be a general fondness for the decimal system causing risk managers to perform correlation calculation (among other calculated measures, such as volatilities) within 10 years of historical data. Unfortunately, this time window now excludes events during the financial market crisis of 2007-2008. Instead, it reflects a somewhat unique and non-representative period during which central banks were exploring "unconventional" policy measures (such as quantitative easing) and some interest rates were pushing into negative territory. As of lately, the market dynamics on the back of COVID-19 is influencing calculation, making the recent data set potentially non-representative of the future as well.

Supervisors should keep a close eye on the type of data sets used to calibrate correlation matrices and ensure that periods of financial market stress are included as well.

\subsection{Reverse Stress Testing}

Reverse stress tests supplement regular stress tests by explicitly identify and assess the tail risk scenarios most likely to render business models unviable, that can cause a bank to default [20]. Making appropriate extreme correlation assumptions can reveal hidden vulnerabilities in banks' business models. Because each institution has a different balance sheet composition, correlation tail risk needs to be defined individually. 


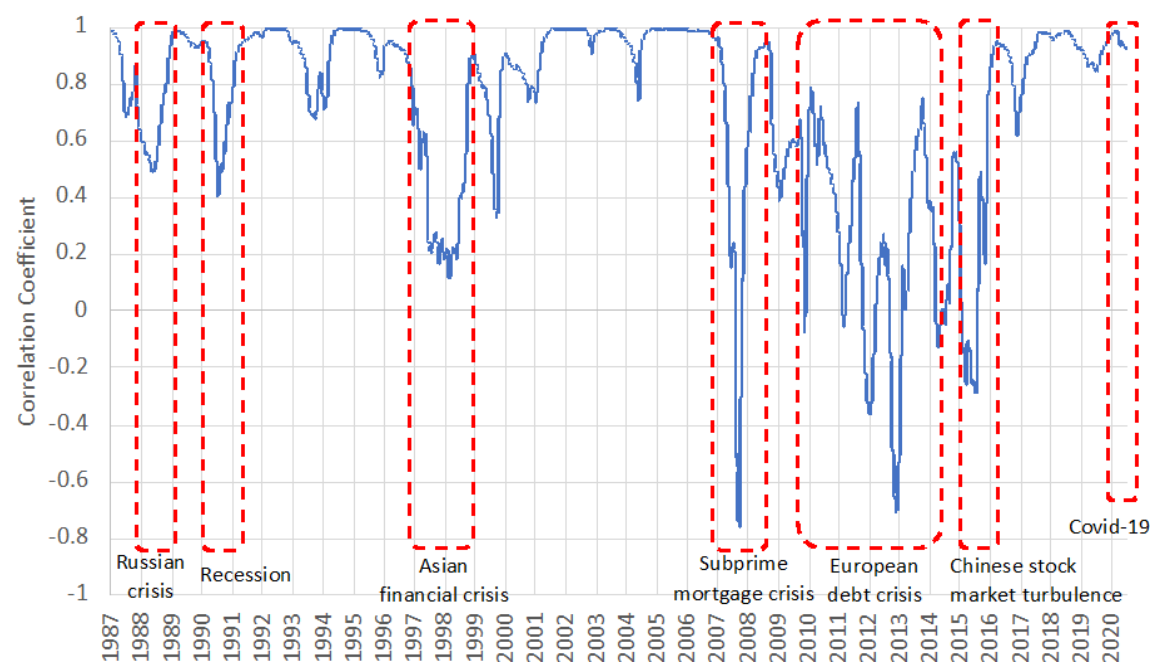

Figure 7. Rolling correlation between 3-month US Government yield and 3-month TED spreads $^{23}$.

For example, a bank that holds $€ 100 \mathrm{~m}$ in corporate loans and receives fixed on a $€ 100 \mathrm{~m}$ interest-rate (IR) swap in an attempt to diversify between corporate spreads and swap spreads faces the most severe impact on its balance sheet if the correlation between corporate spreads and swap spreads goes to +1 . In this case a general spread widening (maybe on the back of a looming crisis) will impact corporate loans and swaps equally, with no mitigating diversification effects. However, for another bank that combines the same $€ 100 \mathrm{~m}$ corporate loan book with a $€ 100 \mathrm{~m}$ pay-fixed interest rate swap (in an attempt to neutralize the exposure to changes in general interest rates) will be most negatively affected by correlation between corporate spreads and swap spreads approaching -1 during a crisis. Here, widening corporate spreads will adversely affect the market value of the corporate loan portfolio, while the narrowing of swap spreads causes an additional mark-to-market loss of the pay-fixed interest rate swap (all else being equal).

Identifying the most severe correlation scenario either requires an intimate knowledge of a bank's balance sheet positions or to simulate a large number of trials with various correlation assumptions to ferret out the most severe tail factors. Supervisors should verify that this is diligently done.

\subsection{Recovery Planning}

Part of stress testing is a recovery plan outlining the proposed recovery actions in case a severe shock to a bank's balance sheet. Such an adverse scenario could be triggered by a substantial change in prices of one asset class that has knock-on effects onto other asset classes. The extent to which shocks propagate throughout the financial product universe is also a function of actual correlations between asset classes.

${ }^{23}$ Rolling one-year correlation calculated from daily data; data up to 19 June 2020; source: Federal Reserve Bank of St. Louis Economic Data. 
During the financial market crisis, some products not only developed extreme correlations, but also became illiquid at the same time. Often, financial institutions discover the painful truth during times of stress that they all have similar or identical positions on their book, causing hedging and liquidation flows in the market to become one-way. Apart from the price effect, this leads many market participants formerly trusted to be liquidity providers (including universal banks, hedge funds etc.) to withdraw from the market, at least temporarily, causing, at the extreme, some instruments to be quoted as "zero bid, no offer". Of course, once an asset is quoted as "zero bid, no offer", its correlation to other financial instruments becomes a moot point.

Supervisors should therefore question whether in scenarios of extreme correlation between certain asset classes not only market risk materializes (due to a reduction of diversification benefits) but also a significant risk of liquidity risk. A recovery plan looks different for a bank that faces a zero-correlation between two balance sheet positions that are both actively traded in liquid markets, compared to a bank that observes the same zero-correlation, but only because one of the two balance sheet items is no longer actively quoted in the market.

\section{Conclusion}

Correlation assumptions are directly linked to a bank's capital requirements via risk estimates such as Value-at-Risk (VaR) that use correlation as an input parameter. We have shown that correlation is plagued by a number of issues that include volatility, directionality and autocorrelation. Because portfolio risk is a concave function of correlation, an increase in volatility of correlation does not reduce expected portfolio diversification benefits. Therefore, the strong emphasis on changing correlation in related literature may not be justified. However, directionality and autocorrelation of correlation are more problematic. Directionality removes diversification benefits when they are most needed, i.e. in a crisis, and autocorrelation amplifies correlation and makes it more persistent, creating the illusion of stable, reliable correlation levels. Additionally, the reaction function of correlation changes to market crises depends on the type of crisis. First lessons from the COVID-19 pandemic are that correlations have not changed the same way as, say, during the 2007/2008 financial market crisis. Prudent bank risk management should take this into consideration when calibrating its risk models to historical correlation levels. Market price-based stress tests should include various levels of assumed correlation as inputs to the statistical models used to assess a bank's viability. Banking supervisors and macro prudential authorities play an important role in challenging banks' correlation assumptions as well as confirming the rigor of applying them.

\section{Conflicts of Interest}

The author declares no conflicts of interest regarding the publication of this paper. 


\section{References}

[1] Basel Committee on Banking Supervision (2009) Principles for Sound Stress Testing Practices and Supervision. https://www.bis.org/publ/bcbs155.htm

[2] Basel Committee on Banking Supervision (2018) Stress Testing Principles. https://www.bis.org/bcbs/publ/d450.htm

[3] Bundesanstalt für Finanzdienstleistungsaufsicht (2018) BaFinJournal November 2018.

https://www.bafin.de/SharedDocs/Downloads/DE/BaFinJournal/2018/bj_1811.html

[4] Basel Committee on Banking Supervision (2017) Supervisory and Bank Stress Testing: Range of Practices. https://www.bis.org/bcbs/publ/d427.html

[5] Basel Committee on Banking Supervision (2019) Minimum Capital Requirements for Market Risk. https://www.bis.org/bcbs/publ/d457.pdf

[6] Driessen, J. and Maenhout, P.J. and Vilkov, G. (2009) The Price of Correlation Risk: Evidence from Equity Options. The Journal of Finance, 64, 1377-1406. https://doi.org/10.1111/j.1540-6261.2009.01467.x

[7] Mueller, P., Stathopoulos, A. and Vedolin, A. (2017) International Correlation Risk. Journal of Financial Economics, 126, 270-299. https://doi.org/10.1016/j.jfineco.2016.09.012

[8] Sandoval Jr., L. and De Paula Franca, I. (2012) Correlation of Financial Markets in Times of Crisis. Physica A: Statistical Mechanics and Its Applications, 391, 187-208. https://doi.org/10.1016/j.physa.2011.07.023

[9] Longin, F. and Solnik, B. (2001) Correlation Structure of International Equity Markets during Extremely Volatile Periods. Journal of Finance, 56, 649-676. https://doi.org/10.1111/0022-1082.00340

[10] Ang, A. and Bekaert, G. (2002) International Asset Allocation with Regime Shifts. The Review of Financial Studies, 15, 1137-1187. https://doi.org/10.1093/rfs/15.4.1137

[11] Öztek, M.F. and Öcal. N. (2017) Financial Crises and the Nature of Correlation between Commodity and Stock Markets. International Review of Economics and Finance, 48, 56-68. https://doi.org/10.1016/j.iref.2016.11.008

[12] Krishnan, C.N.V., Petkova, R. and Ritchken, P. (2009) Correlation Risk. Journal of Empirical Finance, 16, 353-367. https://doi.org/10.1016/j.jempfin.2008.10.005

[13] Chua, D.B., Kritzman, M. and Page, S. (2009) The Myth of Diversification. Journal of Portfolio Management, 36, 26-35. https://doi.org/10.3905/JPM.2009.36.1.026

[14] Bogle, J.C. (2016) The Index Mutual Fund: 40 Years of Growth, Change, and Challenge. Financial Analysts Journal, 72, 9-13. https://doi.org/10.2469/faj.v72.n1.5

[15] Zuckermann, G., Levy, R., Timiraos, N. and Banerji, G. (2018) Behind the Market Swoon: The Herdlike Behavior of Computerized Trading. The Wall Street Journal, 25 December 2018.

[16] Carlos, E.J. and Lobato, I.N. (2009) Testing the Martingale Hypothesis. In: Mills T.C. and Patterson K., Eds., Palgrave Handbook of Econometrics. Palgrave Macmillan, London, 972-1003. https://doi.org/10.1057/9780230244405_20

[17] Buss, A., Schönleber, L. and Vilkov, G. (2018) Expected Stock Returns and the Correlation Risk Premium. CEPR Discussion Papers 12760.

[18] Grossman, S.J. and Miller, M.H. (1988) Liquidity and Market Structure. Journal of Finance, 43, 617-633. https://doi.org/10.1111/j.1540-6261.1988.tb04594.x

[19] Gatev, E., Goetzmann, W.N. and Rouwenhorst, K.G. (2006) Pairs Trading: Performance of a Relative-Value Arbitrage Rule. The Review of Financial Studies, 19, 
797-827. https://doi.org/10.1093/rfs/hhj020

[20] Moody's (2013) Moody's Analytics Risk Perspectives-Stress Testing European Edition, Vol. 1. 